\title{
Metabolic changes in pregnancy relevant to diabetes mellitus
}

\author{
T. LIND \\ M.B., Ph.D., M.R.C.O.G. \\ MRC Reproduction and Growth Unit, Princess Mary Maternity Hospital, Newcastle upon Tyne
}

\begin{abstract}
Summary
The alterations in carbohydrate metabolism during pregnancy are discussed and possible mechanisms for these changes are put forward. It is stressed that the raised levels of plasma glucose, the enhanced response to insulin and the decreased tissue sensitivity to insulin are all features of normal pregnancy. It may be difficult to distinguish this from very early forms of diabetes mellitus during pregnancy, the detection of which is briefly considered.
\end{abstract}

\section{Introduction}

While doctors agree that there is a range of 'normal' physiological values many seem to believe that there are relatively narrow limits to this range and any conspicuous deviation from it can only be caused by disease. Yet even among healthy people there must be allowances for age, sex and 'fitness'; it is improbable that the physiological responses of a 20-year-old male athlete are indistinguishable from those of a 60-year-old housewife. This comparison would no doubt be judged unfair by most doctors because the differences in physiological status would be self-evident. But pregnancy induces major physiological adaptations in the mother which are less obvious but may, in some instances, be so marked as to mimic disease. The changes occurring in carbohydrate metabolism are a particularly good example because allowances are rarely made for any pregnancy effect when 'diabetes' is suspected. It is the purpose of the author to discuss in this paper the influence of normal, uncomplicated pregnancy upon carbohydrate metabolism and help to define the circumstances in which true diabetes mellitus might be suspected.

\section{Pregnancy influence upon carbohydrate metabolism}

All the data to be described have been obtained using a standard $50 \mathrm{~g}$ oral glucose tolerance test (OGTT) unless some other procedure is specified. The reasons for the preference of this test over the intravenous glucose tolerance test have been discussed elsewhere (Lind, 1975).

\section{Fasting plasma values}

Glucose. It is generally accepted that the fasting plasma glucose value is lower during pregnancy (Bleicher, O'Sullivan and Freinkel, 1964; Tyson and Merimee, 1970) but the exact timing of this change has been generally attributed to the first trimester. Lind, Billewicz and Brown (1973) in a longitudinal study of 19 healthy women performed a standard $50 \mathrm{~g}$ OGTT at 10, 20, 30 and 38 weeks' gestation and again at 10-12 weeks after delivery, the same patients therefore acting as their own non-pregnant control group. The fasting concentration was significantly lower than the non-pregnant value by 10 weeks of pregnancy but there was no significant decrease thereafter (Table 1).

TABLE 1. The fasting and 2-hr plasma glucose and insulin concentrations throughout pregnancy and 10-12 weeks post partum in 19 healthy women following a $50 \mathrm{~g}$ OGTT together with the time at which the peak plasma glucose and insulin values occurred

\begin{tabular}{|c|c|c|c|c|c|c|}
\hline \multirow{2}{*}{ Value } & & \multicolumn{5}{|c|}{ Gestation (weeks) } \\
\hline & & PN & 10 & 20 & 30 & 38 \\
\hline Fasting & $\begin{array}{l}\text { glucose } \\
\text { insulin }\end{array}$ & $\begin{array}{l}4 \cdot 6 \\
5 \cdot 5\end{array}$ & $\begin{array}{l}4 \cdot 2 \\
4 \cdot 5\end{array}$ & $\begin{array}{l}4 \cdot 0 \\
4 \cdot 5\end{array}$ & $\begin{array}{l}4 \cdot 2 \\
7 \cdot 0\end{array}$ & $\begin{array}{l}3.9 \\
7 \cdot 5\end{array}$ \\
\hline $2-\mathrm{hr}$ & $\begin{array}{l}\text { glucose } \\
\text { insulin }\end{array}$ & $\begin{array}{r}4 \cdot 3 \\
12 \cdot 3\end{array}$ & $\begin{array}{r}4.9 \\
18 \cdot 1\end{array}$ & $\begin{array}{r}3.9 \\
15.9\end{array}$ & $\begin{array}{r}4 \cdot 4 \\
22 \cdot 4\end{array}$ & $\begin{array}{r}4 \cdot 5 \\
27 \cdot 0\end{array}$ \\
\hline Peak time (min) & $\begin{array}{l}\text { glucose } \\
\text { insulin }\end{array}$ & $\begin{array}{l}34 \cdot 1 \\
44 \cdot 1\end{array}$ & $\begin{array}{l}34 \cdot 7 \\
40 \cdot 8\end{array}$ & $\begin{array}{l}36 \cdot 5 \\
45 \cdot 8\end{array}$ & $\begin{array}{l}47 \cdot 7 \\
53 \cdot 7\end{array}$ & $\begin{array}{l}55 \cdot 0 \\
57 \cdot 4\end{array}$ \\
\hline
\end{tabular}

glucose $(\mathrm{mmol} / \mathrm{l})$; insulin $(\mu \mathrm{u} . / \mathrm{ml}) ; \mathrm{PN}-10-12$ weeks postnatal; OGTT, oral glucose tolerance test.

Insulin. This does not change in the same way as glucose. The same group of women had a small but statistically significant rise in fasting insulin concentration - but by the end of pregnancy. The timing was thus different and seems to preclude any causeand-effect relation between fasting glucose and insulin levels (Table 1). Similar findings were reported by Kühl and Holst (1976).

Glucagon. In a study of 8 normal healthy women having a standard OGTT between 16 and 24 weeks' gestation, again between 35 and 38 weeks' gestation and finally 6-8 weeks post partum, Kühl and Holst (1976) found the fasting plasma glucagon to be 
significantly elevated during late pregnancy relative to the postpartum value $(153 \cdot 7 \pm 17 \cdot 2 \mathrm{pg} / \mathrm{ml} \mathrm{com-}$ pared to $118 \cdot 1 \pm 10 \cdot 1 \mathrm{pg} / \mathrm{ml}$ ).

Despite the raised fasting glucagon levels in late pregnancy, the plasma glucose values do not increase; this is probably because the increase in plasma insulin concentration is proportionately greater at this time. The same authors found the fasting ratio of insulin to glucagon to be $1 \cdot 8 \pm 0.4$ during late pregnancy but $1 \cdot 1 \pm 0 \cdot 2$ post partum when compared on a molar basis.

\section{Response to an oral glucose load}

Glucose response. As pregnancy progresses, the time to reach the maximum glucose concentration increases; in the subjects studied by Lind et al (1973) the mean time to the peak plasma glucose level was $55 \mathrm{~min}$ at 38 weeks' gestation compared to the non-pregnant value of $34 \mathrm{~min}$. Despite this delay the fasting level is still regained by $2 \mathrm{hr}$ in most women (Table 1).

Insulin response. The effect of pregnancy upon the insulin response is even more striking. The peak value increases progressively and the time to reach the maximum concentration is delayed. By $2 \mathrm{hr}$ the level is still well above the fasting concentration (Table 1).

Glucagon response. During late pregnancy the decrement in plasma glucagon values following a glucose load is greater than post partum; the nadir is also reached later. Post partum the lowest glucagon concentration is achieved at about $60 \mathrm{~min}$ but is delayed to 120 min during late pregnancy (Kuhl and Holst, 1976).

\section{Possible explanations for these pregnancy effects}

There are several theoretical possibilities which can be considered:

\section{Inadequate maternal insulin production}

While the maternal insulin response is increased during pregnancy it could reflect her maximum production rate and still be insufficient to maintain 'normal' glucose homoeostatis. During a study of renal reabsorption of glucose performed in the MRC Reproduction and Growth Unit, Newcastle upon Tyne, 10 women were infused with dextrose solution at 16, 26 and 36 weeks' gestation and again 10-12 weeks post partum. The idea was to achieve a stable plasma glucose concentration of about $11.3 \mathrm{mmol} / \mathrm{l}$ at each stage of pregnancy and to maintain this for at least $80 \mathrm{~min}$; the mean values achieved at each stage of pregnancy are given in Table 2 . The change in insulin response as pregnancy progressed was quite dramatic; using the average values at $80 \mathrm{~min}$ infusion time, the insulin concentration increased from a non-pregnant value of $66 \mu \mathrm{u}$./ml to $199 \mu \mathrm{u}$./
TABle 2. Plasma glucose $(\mathrm{mmol} / \mathrm{l})$ and insulin $(\mu \mathrm{u} . / \mathrm{ml})$ concentrations during glucose infusions at various stages of pregnancy

\begin{tabular}{|c|c|c|c|c|c|}
\hline \multirow{2}{*}{$\begin{array}{l}\text { Gestation } \\
\text { (weeks) }\end{array}$} & & \multicolumn{4}{|c|}{ Infusion time (min) } \\
\hline & & 0 & 40 & 60 & 80 \\
\hline $10-12 \mathrm{PN}$ & $\begin{array}{l}\text { glucose } \\
\text { insulin }\end{array}$ & $\begin{array}{l}5 \cdot 0 \\
5 \cdot 7\end{array}$ & $\begin{array}{l}12 \cdot 9 \\
35 \cdot 1\end{array}$ & $\begin{array}{l}12 \cdot 5 \\
48 \cdot 9\end{array}$ & $\begin{array}{l}12 \cdot 9 \\
66 \cdot 4\end{array}$ \\
\hline 16 & $\begin{array}{l}\text { glucose } \\
\text { insulin }\end{array}$ & $\begin{array}{l}4 \cdot 3 \\
6 \cdot 6\end{array}$ & $\begin{array}{l}10 \cdot 1 \\
79 \cdot 5\end{array}$ & $\begin{array}{l}10 \cdot 0 \\
87.5\end{array}$ & $\begin{array}{l}10 \cdot 0 \\
89 \cdot 5\end{array}$ \\
\hline 26 & $\begin{array}{l}\text { glucose } \\
\text { insulin }\end{array}$ & $\begin{array}{r}4 \cdot 4 \\
12 \cdot 7\end{array}$ & $\begin{array}{l}10 \cdot 9 \\
93 \cdot 0\end{array}$ & $\begin{array}{l}10 \cdot 9 \\
94 \cdot 2\end{array}$ & $\begin{array}{r}10.9 \\
115.6\end{array}$ \\
\hline 36 & $\begin{array}{l}\text { glucose } \\
\text { insulin }\end{array}$ & $\begin{array}{l}4 \cdot 6 \\
16\end{array}$ & $\begin{array}{r}11 \cdot 0 \\
130 \cdot 2\end{array}$ & $\begin{array}{r}11 \cdot 8 \\
163 \cdot 2\end{array}$ & $\begin{array}{r}11 \cdot 8 \\
198 \cdot 6\end{array}$ \\
\hline
\end{tabular}

PN - Postnatal.

$\mathrm{ml}$ at 36 weeks' gestation. It seems probable that pregnant women can increase their insulin production whenever needed; the apparently limited response during pregnancy is therefore likely to be a specific physiological adjustment rather than an inability on the part of the mother to produce more insulin.

\section{Increased proinsulin production}

In the insulin immunoassay used in this unit (Lind et al., 1972) the antibody (Burroughs Wellcome RD 10) reacts with proinsulin almost as well as with insulin (proinsulin/insulin cross-reaction $0 \cdot 86 / 1 \cdot 0$ ) As proinsulin is only about one fifth as biologically active as insulin any increase from this source would be shown by immunoassay but not reflected in glucose control. However, in the present patients, separation of proinsulin from insulin by column chromatography and subsequent assay of the fractions has failed to show any increase in circulating proinsulin concentrations during pregnancy. Similar findings have been reported by others (Phelps et al., 1975; Kühl, 1977).

\section{Insulin metabolism}

The raised amount of circulating insulin could be due to a decreased clearance rate from the circulation rather than an increase in production. To study this possibility women were chosen at 34-38 weeks gestation as being in good general health, free of any family history or other stigmata of diabetes and having an uncomplicated pregnancy. After an overnight fast of at least $12 \mathrm{hr}$, each was given an intravenous bolus of insulin on the basis of $0.02 \mathrm{u} . / \mathrm{kg}$ body weight. The test was repeated at 10 weeks post partum and again after a further interval of 4 weeks. During the last occasion an infusion of growth hormone release inhibitory hormone (GHRIH or 
somatostatin) was given to inhibit any endogenous insulin production. The calculated half-life of insulin on each occasion was about 3.5 min showing that pregnancy has no effect on the kinetics of insulin (Lind et al., 1977). This is in keeping with the report of Bellmann and Hartmann (1975) using human data and natural rather than radioiodinated insulin.

\section{Glucose tolerance factor}

It has been suggested that chromium, incorporated into a specific organic complex in the body, named glucose tolerance factor (GTF), is a necessary intermediary between the insulin molecule and its cell membrane receptors (Mertz, 1967). If this is so, a deficiency of GTF could explain those forms of carbohydrate disturbance in which high plasma glucose concentrations are associated with normal or increased plasma insulin values such as maturity onset diabetes and pregnancy (Glinsmann, Feldman and Mertz, 1966; Hambidge, 1971). In a Western society, depletion of chromium stores because of dietary deficiency is unlikely, but a relative deficiency state might result from a reduced ability to absorb chromium, an inability to convert sufficient inorganic chromium into the active organic form, GTF, or from an increased urinary excretion of chromium or GTF. The first 2 possibilities might account for some of the milder forms of diabetes mellitus while the third possibility could account for the changes in carbohydrate response during pregnancy. The physiological increase in glomerular filtration rate might lead to an increased urinary loss of chromium, or GTF, which in some pregnant women, may cause 'carbohydrate intolerance'

To test this hypothesis 20 healthy, non-diabetic, pregnant women aged 21-23 years were recruited; after random allocation 10 were asked to take brewer's yeast (a natural compound rich in GTF (Mertz, 1967)) and 10 acted as control subjects. All of these patients were subsequently delivered of healthy infants after uncomplicated pregnancies.

Each patient fasted overnight for at least $12 \mathrm{hr}$ and then had a standard $50 \mathrm{~g}$ OGTT; this first test was undertaken at about 30 weeks' gestation. The 10 patients being tested were then asked to take $10 \mathrm{~g} /$ day of brewer's yeast (Saccharomyces uvarum [= carlsbergensis] $)$ in fruit juice; this contains about $11 \mu \mathrm{g}$ of GTF (Toepfer et al., 1973). The control subjects drank the same volume of fruit juice daily After 2 weeks the OGTT was repeated.

A more elaborate test programme was undertaken in 11 maturity onset diabetic patients controlled by diet alone, and in 17 non-pregnant women. These women were tested at regular intervals during the menstrual cycle because of the known variation in the OGTT response curve during the follicular and luteal phases.
Paired $t$-tests were used to show the variability between tests within patients; there was considerable test variation in the pregnant, non-pregnant and diabetic subjects but no 'improvement' whatsoever in carbohydrate tolerance in any of the subjects studied, whether or not they took yeast.

It would seem unlikely that deficiency of chromium or GTF is a major cause of carbohydrate intolerance during pregnancy in a Western society.

\section{Insulin resistance}

Tissue resistance to insulin effect can be implied from 3 main findings: the increased insulin response to a glucose stimulus, the reduced peripheral uptake of glucose and finally the change in glucagon response.

Insulin response to glucose. The increase in circulating insulin levels has been discussed previously and summarized in Tables 1 and 2. By term, the fasting level has increased, more circulating insulin is found $2 \mathrm{hr}$ after a glucose load, and glucose infusions promote an enhanced insulin response.

Reduced peripheral uptake of glucose. In the reported study of insulin half-life (Lind et al., 1977) it was found that an intravenous dose of insulin of $0.02 \mathrm{u} . / \mathrm{kg}$ body-weight given to fasted pregnant women at about 36 weeks' gestation reduced the fasting plasma glucose by about one $\mathrm{mmol} / \mathrm{l}$. A similar dose given to the same women 10-12 weeks after delivery reduced the fasting level by about $1.8 \mathrm{mmol} / \mathrm{l}$.

Glucagon response. Four women in the above study had their glucagon determined by a specific immunoassay which cross-reacted to less than $0.1 \%$ with human gut glucagon (Kühl and Holst, 1976). Blood samples were obtained at one-min intervals for $3 \mathrm{~min}$ before the insulin injection; the concentrations of plasma glucose, insulin and glucagon were determined and the means of the 3 measurements in each patient taken as the normal 'fasting levels'. After injection of the insulin one min was allowed for mixing then further blood samples were obtained at one-min intervals for $30 \mathrm{~min}$; full details of the methods have been published elsewhere (Lind et al., 1977). The mean peak insulin value for the 4 patients in late pregnancy was $210 \mu \mathrm{u} . / \mathrm{ml}$ and the fasting insulin level was regained in each patient by about $19 \mathrm{~min}$; essentially similar findings were recorded when the test was repeated 10-12 weeks after delivery. During late pregnancy (35-39 weeks) the insulin-induced hypoglycaemia appeared to stimulate a small glucagon response; while this response was somewhat erratic, the values tended to remain above the fasting concentration. In the non-pregnant state the glucagon values were depressed below the fasting value for about $22 \mathrm{~min}$, i.e. when the injected insulin had largely disappeared. This suggests that 
the pancreatic islet cells are less sensitive to the effects of circulating insulin during pregnancy.

\section{Preliminary conclusions}

These data were all derived from perfectly healthy women having uncomplicated pregnancies, and the same women acted as their own non-pregnant control group. Thus 'carbohydrate intolerance' manifested as higher plasma glucose values, an enhanced insulin response, and a decreased tissue sensitivity to insulin are features of normal pregnancy. Why these changes occur is difficult to define; the altered hormonal milieu of pregnancy is usually held to be responsible and this is probably so. Certainly the changes rapidly revert to normal after delivery (Lind and Harris, 1976). However it would be an oversimplification to hold any one hormone, such as human placental lactogen, responsible; the whole complex of altered maternal adaptations, including changes in protein and fat metabolism, probably combine to influence changes in carbohydrate homoeostasis. The clinical problem is to define the upper limit of the normal range of pregnancy responses from the early forms of diabetes mellitus.

The diagnosis of disordered carbohydrate metabolism

The practice of detecting diabetes mellitus from the presence of glycosuria is based upon the fact that a significant increase in blood glucose will produce a filtered load of glucose in the proximal renal tubule which the kidney is incapable of absorbing. This is not true of pregnancy; about $50 \%$ of all healthy, pregnant women have glycosuria at some stage while their blood glucose levels remain well within normal limits (Davison and Hytten, 1975). This is not, therefore, a sufficiently selective screening procedure for antenatal clinics; if the obstetrician wishes to detect women with abnormally elevated blood glucose concentrations, then it is blood glucose which ought to be determined.

\section{Glycosylated haemoglobin}

Space does not permit of a detailed account of the development of the glysocylated haemoglobins, currently denoted as $\mathrm{Hb} \quad \mathrm{A}_{1(\mathrm{a}+\mathrm{b}+\mathrm{c})}$, as possible monitors of diabetic status and the reader is referred to Rahbar (1968); Trivelli, Ranney and Lai (1971); Bunn et al. (1976); Fitzgibbons, Koler and Jones (1976) and Koenig et al. (1976) among others. In essence it appears that the glycosylated haemoglobins form some $6-8 \%$ of the total haemoglobin in a normal healthy population but about $12-14 \%$ in reasonably well controlled insulin-dependent diabetics. As these haemoglobins are slow to form and relatively irreversible once formed they may offer a method of checking long-term blood glucose control in treated diabetics. The longer the blood glucose concentration remains elevated the greater will be

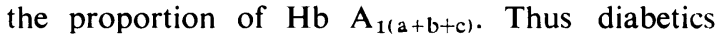
attending a clinic will have their immediate status determined by blood or urinary glucose profiles, but a knowledge of the proportion of glycosylated haemoglobin may allow the clinician to assess what degree of control the patient has achieved over the previous 4-8 weeks.

The possible roles for these haemoglobins can be considered by the obstetrician: (i) such determinations may offer a further method of controlling pregnant diabetic patients and (ii) they may offer a screening method for unsuspected diabetes during pregnancy.

\section{References}

Bellman, O. \& HartmanN, E. (1975) Influence of pregnancy on the kinetics of insulin. American Journal of Obstetrics and Gynecology, 122, 829.

Bleicher, S.J., O’Sullivan, J.B. \& Freinkel, N. (1964) Carbohydrate metabolism in pregnancy. 5. The interrelations of glucose, insulin and free fatty acids in late pregnancy and post-partum. New England Journal of Medicine, 271, 866.

BunN, H.F., Haney, D.N., Kamin, S., Gabbay, K.H. \& GalloP, P.M. (1976) The biosynthesis of human hemoglobin $\mathrm{A}_{1 \mathrm{c}}$. Journal of Clinical Investigation, 57, 1652.

DAvison, J.M. \& HytTen, F.E. (1975) Renal handling of glucose in pregnancy. In: Carbohydrate Metabolism ing
Pregnancy and the Newborn (Ed. by Sutherland, H.M. \& Stowers, J.M.). Churchill Livingstone, Edinburgh.

Fitzgibions, J.F., Koler, R.D. \& Jones, R.T. (1976) Red? cell age-related changes in hemoglobin $\mathbf{A}_{1(\mathbf{a}+b)}$ and $\mathbf{A}_{1} \mathrm{c}$ in normal and diabetic subjects. Journal of Clinical Investigation, 58, 820 .

Glinsmann, W.H., Feldman, F.J. \& Mertz, W. (1966) Plasma chromium after glucose administration. Science, 152, 1243.

Hambidge, K.M. (1971) Chromium nutrition in the mother and the growing child. In: Newer Trace Elements in Nutrition (Ed. by Mertz, W. \& Cornatzer, W.E.) pp. 169-194. Marcel Dekker, New York.

Koenig, R.J., Peterson, C.M., Jones, R.L., Saudek, C. Lehrman, M. \& Cerami, A. (1976) Correlation of glucose regulation and hemoglobin $\mathrm{A}_{1 \mathrm{c}}$ in diabetes mellitus. New England Journal of Medicine, 295, 417.

KüHL, C. (1977) Serum insulin and plasma glucagon in human pregnancy-or the pathogenesis of gestational diabetes. A review. Acta diabetica latanica, 14, 1.

KüHL, C. \& Holst, J.J. (1976) Plasma glucagon and the insulin : glucagon ratio in gestational diabetics. Diabetes, 25, 16.

LIND, T. (1975) Changes in carbohydrate metabolism during pregnancy. In: Clinics in Obstetrics and Gynaecology (Ed. by Hytten, F.E.) p. 395. W. B. Saunders Co., London.

Lind, T., Bell, S., Gilmore, E., Huisjes, H.J. \& Schally, A.V. (1977) Insulin disappearance rate in pregnant and non-pregnant women, and in non-pregnant women given GHRIH. European Journal of Clinical Investigation, 7, 47.

Lind, T., Billewicz, W.Z. \& Brown, G. (1973) A serial study of changes occurring in the oral glucose tolerance test during pregnancy. Journal of Obstetrics and Gynaecology of the British Commonwealth, 80, 1033.

LIND, T. \& HARRIS, V.G. (1976) Changes in the oral glucose tolerance test during the puerperium. British Journal of Obstetrics and Gynaecology, 83, 460. 
Lind, T., Van de Groot, H.A., Brown, G. \& Cheyne, G.A. (1972) Observations on blood glucose and insulin determinations. British Medical Journal, 3, 320.

MERTZ, W. (1967) Biological role of chromium. Federation Proceedings, 26, 86.

Phelps, R.L., Bergenstal, R., Freinkel, N., Rubenstein, A.H., Metzger, B.E. \& MaKo, M.E. (1975) Carbohydrate metabolism in pregnancy: XIII. Relationship between plasma insulin and proinsulin during late pregnancy in normal and diabetic subjects. Journal of Clinical Endocrinology, 41, 1085.
Rahbar, S. (1968) An abnormal haemoglobin in the red cells of diabetics. Clinica chimica acta, 22, 296.

Toepfer, E.W., Mertz, W., Roginski, E.E. \& Polansky, M.M. (1973) Chromium in feeds in relation to biological activity. Journal of Agricultural Food Chemistry, 21, 69.

Trivelli, L.A., RanNey, H.M. \& Lai Hong-Tien (1971) Hemoglobin components in patients with diabetes mellitus. New England Journal of Medicine, 284, 353.

Tyson, J.E. \& Merimee, T.J. (1970) Some physiological effects of protein ingestion in pregnancy. American Journal of Obstetrics and Gynecology, 107, 797. 